\title{
Formação Compartilhada: relato de experiências sobre o Estágio Supervisionado em História no Colégio de Aplicação da Universidade Federal de Uberlândia (UFU)
}

\author{
Christian Alves ${ }^{1}$ \\ Gabriel Marques Fernandes ${ }^{2}$
}

\begin{abstract}
RESUMO
O artigo 82 da Lei Federal $n^{\circ}$ 9.394/96 e o Decreto Nacional $n^{\circ} 87.497$ estabelecem os pilares que dão sentido à prática obrigatória do estágio supervisionado no ensino superior. Entretanto, a aplicabilidade das leis gera singularidades ao contato com os espectros de subjetividades do meio concreto. Dessa forma, a prática, a construção das atividades e as formas de abordagem do estágio supervisionado dependem de cada docente orientador, supervisor e discentes. Considerando essas variáveis, este relato de experiência tem como objetivo apresentar a última etapa de uma proposta metodológica válida, desenvolvida no Colégio de Aplicação da Universidade Federal de Uberlândia (CAp - UFU), em turmas do $5^{\circ}$ ano do ensino fundamental, com o intuito de refletir sobre as possibilidades de um estágio baseado no princípio de formação compartilhada envolvendo docentes, discentes e uma "vizinha" da escola, natural da Guiné-Bissau, África.

Palavras-chave: Estágio; Ensino; História.
\end{abstract}

\begin{abstract}
Article 82 of the Brazilian Federal Law no. 9394/1996 and the national Decree no. 87497 established the basis that support the compulsory practice of supervised internships in higher education. However, the applicability of laws creates particularities when it comes to the contact with the range of subjectivities of the concrete environment, i.e. the practice. The creation of activities and forms of approaching the supervised internship will depend on each advisor, supervisor and students. By taking these variables into account, this experience report presents the last stage of a valid methodological proposal developed at Application School, of the Federal University of Uberlândia (Brazil), in classes of the 5th year of elementary school. This proposal reflected on the possibilities of an internship based on the principle of shared training, involving teachers, students and a "neighbor" of the school, a native of Guinea-Bissau, Africa.
\end{abstract}

Keywords: Internship, Teaching, History

${ }^{1}$ Colegio de Aplicação da Universidade Federal de Uberlândia (CAp - UFU)

${ }^{2}$ Graduando em História na Universidade Federal de Uberlândia. Email: gabrielmf027@gmail.com 


\title{
1 Introdução
}

\begin{abstract}
A consciência histórica é, assim, o modo pelo qual a relação dinâmica entre experiência do tempo e intenção no tempo se realiza no processo da vida humana. (O termo "vida" designa, obviamente, mais do que o mero processo biológico, mas sempre também - no sentido mais amplo da expressão - um processo social). Para essa forma de consciência, é determinante a operação mental com a qual o homem articula, no processo de sua vida prática, a experiência do tempo com as intenções no tempo e estas com aquelas. Essa operação pode ser descrita como orientação do agir (e do sofrer) humano no tempo. (RÜSEN, 2001, p. 58).
\end{abstract}

O filósofo e historiador alemão Jorn Rüsen, na obra Razão histórica. Teoria da História: os fundamentos da ciência histórica (2001), analisa o impacto do ensino no processo de desenvolvimento da consciência histórica dos sujeitos, ou seja, em suas formas de se relacionarem, interagirem e perceberem o meio que habitam.

$\mathrm{O}$ excerto anterior aborda este impacto do meio, na formação da consciência individual. A relação de constituição da consciência em Rüsen (2001) é formada por processos divididos didaticamente em objetivos e subjetivos, entendendo-os como fenômenos externos experienciados pelos sujeitos: os objetivos são processos sociais em grande escala que tangenciam a vida da comunidade, já os subjetivos são acontecimentos cirúrgicos do cotidiano, subjetivados e interpretados pela mente.

A consciência histórica, segundo Rüsen (2001), é inerente ao ser humano. Portanto, ao considerarmos a realidade como um efeito de verdade (FOUCAULT, 1982, p. 11), o papel do ensino em História seria fundamental, visto que as noções de fenômenos são constituídas por ausências e representações que advêm de escolhas organizadas a partir de interesses de quem representa. Logo, a realidade não é uma verdade, mas, sim, uma interpretação que se traveste do conceito verdade.

Com isso, é válido implicar que o mundo é assimilado através de representações, logo, a História teria como sentido questionar as representações objetivas subjetivadas pelos sujeitos, estimulando a 
criticidade e a reflexão em relação aos fenômenos sociais, contribuindo para o desenvolvimento de indivíduos autônomos, críticos, ativos socialmente, conscientes de si, empoderados e promotores de transformações.

Nesse panorama, dentro dos limites do estágio supervisionado e tendo como background o ensino de História, como construir uma complexa rede de formação docente válida, de forma que os estudantes envolvidos na prática de ensino vivenciem experiências que favoreçam o despertar de suas consciências históricas?

Não consiste em uma tarefa fácil. Sabemos que a educação contemporânea brasileira advém de um longo processo de transformações, utilizada, inclusive, como aparato para "inculcar "uso-econômico-do-tempo" (THOMPSON, 1998, p. 292). No Brasil, um exemplo da escola como intuito disciplinar de um status quo é o acordo debatido pelo MEC (Ministério da Educação e Cultura) e pela USAID (United States Agency for Internacional Development - Agência dos Estados Unidos para o Desenvolvimento Internacional) entre 1964 e 1968.

Tal acordo previa o alinhamento do ensino superior público brasileiro com o estadunidense no período da ditadura civil-militar, para "um controle ideológico visando uma educação para o trabalho servindo dessa forma aos interesses capitalistas" (VALÉRIO, 2006, p. 5633). Dessa forma, a Lei ${ }^{\circ}$ 5692/713 impactou o ensino básico público: o ensino primário e o médio sofreram reformas, e os ensinos técnico e mercantil foram implementados. Ademais, o acordo exigia de seus sujeitos uma formação exclusiva para o mercado de trabalho, variando os nichos de atuação entre as subjetividades de realidades das comunidades escolares, com resguardo legislativo. Assim, forma-se um efeito de verdade sobre o devir da escola na sociedade.

Em contrapartida, Reinhart Koselleck assevera que:

$\mathrm{Na}$ experiência se fundem tanto a elaboração racional quanto as formas inconscientes de comportamento, que não estão mais, ou que não precisam mais estar presentes no conhecimento. Além disso, na

\footnotetext{
${ }^{3}$ Assinada em 11 de agosto de 1971 pelo general e ex-presidente Emílio G. Médici.
} 
experiência de cada um, transmitida por gerações e instituições, sempre está contida e é conservada uma experiência alheia. Nesse sentido, também a história é desde sempre concebida como conhecimento de experiências alheias. Algo semelhante se pode dizer da expectativa: também ela é ao mesmo tempo ligada à pessoa e ao interpessoal, também a expectativa se realiza no hoje, é futuro presente, voltado para o aindanão, para o não experimentado, para o que apenas pode ser previsto. Esperança e medo, desejo e vontade, a inquietude, mas também a análise racional, a visão receptiva ou a curiosidade fazem parte da expectativa e a constituem (KOSELLECK, 2006, 309-310).

Assim, com outras expectativas e com o reconhecimento da importância das experiências alheias, surgem novos formatos de estágio supervisionado e propostas educativas, como é o caso do Pibid (Programa Institucional de Bolsa de Iniciação à Docência), que se tornou de suma importância para a reflexão do sentido da educação e para a constituição da prática de futuros professores ${ }^{4}$. Portanto, experiências significativas durante a licenciatura seriam fundamentais para a formação de pósteros docentes, como esta que se compartilha neste trabalho.

Este relato baseia-se na regência do estagiário G. M. F. na escolacampo Colégio de Aplicação da Universidade Federal de Uberlândia (CAp UFU), a Eseba (Escola de Educação Básica). A experiência ocorreu durante a disciplina de "Estágio Supervisionado II", ministrada na graduação do Curso de História da Universidade Federal de Uberlândia (UFU), no segundo semestre de 2017, pelo professor doutor G. A. L.. O estagiário foi supervisionado pelo professor doutor C. A. M., responsável pelo ensino de História nas turmas A, B e C do $5^{\circ}$ ano da referida instituição.

\footnotetext{
${ }^{4}$ As reflexões sobre tais sentidos também se dão dentro de embates legislativos, práticos, na constituição de documentos, tais como a Lei das Diretrizes e Bases da Educação nacional (LDB), os Parâmetros Curriculares Nacionais (PCNs), Plano Nacional de Educação (PNE) e até mesmo, mais recentemente, a Base Nacional Comum Curricular (BNCC), dentre outros.
} 


\section{A ideia da regência: orientações acadêmicas, plano de aula e roda de conversa}

Dentre os objetivos específicos do plano de curso de Estágio Supervisionado I (observação), havia, em um dos tópicos, a diretriz de que os estagiários, "a partir da observação ativa, propusessem possibilidades de intervenções pedagógicas nas escolas-campo, a partir do Estágio Supervisionado II"5.

Com essa proposta como principal horizonte, no final da profícua observação feita pelo estagiário, e posteriormente discutida com o professor orientador, foram identificadas objetividades e subjetividades da prática docente do professor supervisor, aproximadas à tríade Rogeriana (BUIATTI, 2013): autenticidade, aceitação e empatia. Ou seja, uma metodologia que não atende a um modelo único de aula, aceitando os educandos em suas subjetividades e limitações, tendo empatia pelo momento que o outro está vivenciando, contribuindo para um ambiente harmônico, afetivo e permissivo, em que, de forma sintética e adaptada, o professor, o facilitador, dá ferramentas para que os estudantes aprendam (FONTANA, 1997).

Ademais, o estagiário, estimulado pelas inquietações e pela experiência prática proporcionada pelo Pibid (do primeiro semestre de 2015 ao primeiro semestre de 2017), já trazia um pressuposto teórico heterodoxo que prezava por uma educação libertadora (FREIRE, 1996) e com o discente no centro (BUIATTI, 2013), proporcionando ferramentas para seu aprendizado.

Diante destas condições e das discussões de consciência histórica e ensino em História, conforme Rüsen, e das influências da área da História Cultural, estagiário e professor supervisor optaram por trabalhar na regência com o conceito de representação.

\footnotetext{
${ }^{5}$ Plano de curso da disciplina de Estágio Supervisionado I, 2017-1, disciplina ministrada pelo Professor Doutor G.A.L..
} 
Compreendendo que a preparação de uma aula é impactada pela noosfera (LEITE, 2007), é indispensável que a mesma se relacione ao: currículo escolar, às diretrizes do ofício, ao tempo pedagógico e à transposição epistemológica do ensino superior para o básico (transposição didática (LEITE, 2007, p. 51)), com o sentido de estimular a reflexão crítica dos sujeitos sob seus repertórios de consciência histórica.

A Eseba, por ser um Colégio de Aplicação, possui um currículo orgânico, inspirado principalmente nos pressupostos dos PCNs. A proposta curricular do segundo ciclo, da qual fazem parte o $4^{\circ}$ e o $5^{\circ}$ ano do ensino fundamental, estava dividida em eixos temáticos:

Diversidade Cultural e Infância: Conceito de cultura e alteridade. Infância: $\mathrm{O}$ que é ser criança no Brasil? Crianças em diferentes tempos e lugares. Infância: mudanças e permanências ao longo da História. Diversidade histórica e contemporânea: valorizando a infância. A criança enquanto cidadã: seus direitos e deveres: o Estatuto da Criança e do Adolescente (ECA). As diversas fontes históricas (textual, iconográficas, sonoras entre outras) utilizadas pelos historiadores na construção dos fatos históricos.

O tempo da/na História e as experiências da infância no Continente Africano: Lei 11.645: História e cultura afrobrasileira e dos povos indígenas no Brasil; O tempo cronológico e sua contagem: dia, mês, ano, década, século, milênio. Instrumentos de medida do tempo criados pelos seres humanos ao longo da História. Diferentes tipos de calendários. (Cristão, Chinês entre outros). Crianças africanas no passado e no presente.

Experiências da infância na cultura Indígena: Modo de brincar e se relacionar em grupo. Imagens e representações das crianças indígenas. Sua relação com o meio ambiente. Narrativas mitológicas. Rituais de passagem.

Meio ambiente: Recursos energéticos, consumo e meio ambiente - A construção de noções históricas e as contradições entre consumo e meio ambiente. -. Apropriações históricas do meio ambiente pelos seres humanos - Pré-história: Imigrações e o povoamento da América. -. Recursos naturais e desenvolvimento das sociedades humanas - Estudo de caso: Crescente fértil. -. Explorações dos recursos naturais e seus aspectos políticos, econômicos e sociais no Brasil - História e meio ambiente: Somos espectadores ou atores da história? - Reapropriações históricas do meio ambiente - Povos indígenas do triângulo mineiro: passado e presente de uma história. -. Movimentos ambientalistas e o debate político contemporâneo.

Territórios: cidade e campo: A cidade como espaço educativo e mutável. Espaços de vivências e sociabilidades - A formação das cidades brasileiras: Diferentes processos. -. Trânsitos econômicos, demográficos e 
culturais entre o campo e a cidade no Brasil - Riquezas brasileiras: do pau-brasil à cana-de-açúcar. - . Manifestações do campo na cidade e da cidade no campo - Em busca de novas riquezas: do ouro ao café. Ocupação histórica do território de Uberlândia e do Triângulo Mineiro De São Pedro de Uberabinha à Uberlândia: o processo de formação e transformação de nosso município. -. Espaços de conflitos e lutas políticas - O Bairro Patrimônio: entre preconceitos e ricas manifestações culturais. $-.^{6}$

Por uma questão de afinidade e planejamento, estagiário e professor supervisor alinharam-se ao desenvolvimento de um plano de aula introdutório sob o tópico: “O Bairro Patrimônio: entre preconceitos e ricas manifestações culturais". Trata-se de uma importante região da cidade de Uberlândia onde se desenvolveu uma comunidade negra muito atuante. Assim, seria a oportunidade de inserir a temática dos conteúdos étnicos e raciais no cotidiano dos discentes, contemplando a Lei $\mathrm{n}^{0} 10.639 / 2003^{7}$.

Para tanto, deliberou-se discutir previamente com os estudantes sobre o conceito de representações imagéticas do Continente Africano, trabalho que também seria fundamentado na Lei das Diretrizes e Bases da Educação Nacional (1996):

I - Participar da elaboração da proposta pedagógica do estabelecimento de ensino;

II - Elaborar e cumprir plano de trabalho, segundo a proposta pedagógica do estabelecimento de ensino;

III - Zelar pela aprendizagem dos alunos;

IV - Estabelecer estratégias de recuperação para os alunos de menor rendimento;

V - Ministrar os dias letivos e horas-aula estabelecidos, além de participar integralmente dos períodos dedicados ao planejamento, à avaliação e ao desenvolvimento profissional;

VI - Colaborar com as atividades de articulação da escola com as famílias e a comunidade. (BRASIL, 1996).

A simulação do ofício no estágio permitiu, por conta do tempo, cumprir os itens II e III. Assim, dando curso a uma formação compartilhada,

\footnotetext{
${ }^{6}$ Currículo do $2^{\underline{0}}$ ciclo estruturado pelo corpo docente da Eseba, em 2015, tangenciando os PCNs do 5ํo ano - História, transversais -, de 1998.

${ }^{7}$ Assinada em 10 de janeiro de 2013, pelo ex-presidente Luís Inácio Lula da Silva.
} 
ao longo do semestre, através de uma relação estreita entre estagiário, professor supervisor e professor orientador, desenvolveu-se as seguintes atividades: o plano de aula, a prática, as ferramentas didáticas, a dinâmica de aula, a avaliação da aula ministrada e uma roda de conversa com intercambistas africanos, dentro das atividades já previstas pelo projeto Bairro-escola, coordenado pelo professor supervisor, tangenciando o item VI.

Enquanto isso, com o início das aulas de Estágio Supervisionado II, no âmbito da universidade, o professor orientador fez um brainstorming para obter ideias de atividades com a turma nas diferentes escolas-campo. Tal atividade foi feita com base na experiência de observação do Estágio Supervisionado I, tendo ficado acordado que as atividades seriam realizadas por equipes, apesar de serem obrigatórios momentos de regência individual ${ }^{8}$.

As regências individuais do estagiário G. M. F. consistiram em aulas na forma expositiva e dialogada cuja título seria "Espaço-tempo: As representações imagéticas do continente africano no livro didático”, com o objetivo de apresentar uma ideia da representação imagética, antiga e contemporânea, do continente africano, rompendo com a perspectiva de que, "desde Hegel, as sociedades asiáticas e africanas eram vistas como sociedades estáticas" (ALMEIDA, 2014, p. 1990).

O conceito de representação foi embasado através de dois historiadores: o francês Roger Chartier, e o italiano Carlo Ginzburg, por meio de uma interlocução entre ambos realizada por Guarato (2009):

O conceito de representação em Chartier se apresenta como alternativa de compreensão do social e cultural da realidade via representação, o real como sentido, ele recebe sentido, é representado. Entretanto, a representação abre espaço para o relativismo das representações, uma vez que tudo só existe enquanto representado, qual é a garantia que fornece ao trabalho histórico certo grau de confiabilidade? Para responder essa questão intimo Carlo Ginzburg e suas reflexões acerca desse

\footnotetext{
${ }^{8}$ Etapa realizada juntamente com o estagiário M.V.B., também graduando em História, cujo objetivo geral do plano de atividades seria "promover a ampliação do arcabouço sociocultural dos discentes do $5^{\mathbf{o}}$ ano em torno das narrativas sobre a figura do Africano e do Indígena de forma crítica, contribuindo para o desenvolvimento da consciência histórica do educando através do expositivo, dialógico e lúdico" (Plano de ensino da equipe, 2017-2).
} 
embaraçoso tema. Logo a princípio Ginzburg diz não se interessar pelo que ele chama de "jogo de espelho" proposto por Chartier referente à lógica de Porty-Royal, que na visão do historiador italiano fez com que o termo representação se vulgarizasse (GINZBURG, 2001: p.85). Enquanto para Chartier e preciso focar as apropriações, Ginzburg ressalta que a narrativa histórica constrói um efeito de verdade, mas para isso a narrativa deve comportar provas. Em suma, Ginzburg privilegia a prova como meio de trazer as práticas em sua narrativa, sendo que essa prova é assegurada pela metodologia, a descrição minuciosa, pela narrativa cuidadosamente elaborada que não é positivista, pois apesar de produzir efeito de verdade, não é a verdade em si. (GUARATO, 2009, p. 6-7).

Essas propriedades da representação e seu efeito de verdade eram o principal ponto que o estagiário gostaria de abordar com a temática, de forma personalizada, embora não com a obrigação de discuti-la profundamente de forma teórica.

Ao longo das reflexões acerca dos conceitos concernentes à imagética da África, estagiário e professor supervisor deliberam como ponto de partida, analisar as imagens do continente africano nos livros didáticos disponíveis na escola para consulta dos estudantes. A aula e o levantamento de imagens coadunavam com o procedimento realizado pelos próprios professores da área de História da referida escola-campo, com a utilização do livro didático de forma crítica e complementar.

Nesse sentido, o objeto imagético é indagado através das seguintes perguntas: Se as representações são efeitos de verdade, elas podem ser confundidas com verdades? Qual é o referencial imagético sobre o continente africano que os sujeitos constroem no processo de desenvolvimento da consciência histórica por meio do ensino em História?

Durante este procedimento, foi identificado pelo estagiário o que a historiadora brasileira Ivete Batista da Silva Almeida já apontou em suas pesquisas:

A construção das representações sobre a África estaria fundamentada a partir na cristalização de imagens e estereótipos que o associavam àquilo que fosse inferior, bizarro e subdesenvolvido. Seriam assim, fruto de uma invenção do olhar etnocêntrico, criada como uma imagem invertida em 
um espelho, para legitimar a identidade de desenvolvimento e racionalidade eurocêntrica. (ALMEIDA, 2014, p. 1991).

Em linhas gerais, a maioria das imagens da África eram representações de mapas do continente, sem especificações regionais, para contar uma História europeia, tornando o continente um mero apêndice da História do mediterrâneo.

Outra questão importantíssima é a seção exclusiva para o Egito, como se o país ficasse fora do continente africano, além das representações da África como antiga, estática, ou, contemporaneamente, miserável. Sendo assim, o referencial imagético construía um efeito de verdade moldado por prismas eurocêntricos e estereotipados, e contraditando a Lei $\mathrm{n}^{\mathrm{o}}$ 10.639/2003, que permite a inclusão curricular do referido continente e suas culturas, fazendo com que:

... os autores e professores, revissem sua forma de olhar a história, valorizando o que antes se via ausente dos compêndios, trazendo à luz, histórias, processos e costumes fundamentais para a compreensão da cultura brasileira e sobretudo, dando vida ao esforço de historiados africanos e africanistas, pela compreensão da cultura afro-americana, a partir da compreensão da complexidade do universo africano. (Idem, 2014, p. 1991).

Desse modo, seria indispensável para um estagiário de História, que se propõe a trabalhar África no ensino fundamental e que tenha como propósito construir um espaço para o desenvolvimento da consciência histórica crítica, colocar em questão tais problemáticas das representações. Contudo, como transpor um tema tão delicado para o $5^{\circ}$ ano?

A proposta de regência constituía-se em uma aula de cinquenta minutos dividida em três momentos: O primeiro sendo uma etapa expositiva-dialogada, em que seria discutido o conceito de representação, a pluralidade do continente africano e como são apresentados os elementos no livro didático da escola através das imagens. Para tanto, o estagiário utilizaria de aproximações com a realidade dos discentes por meio de uma 
dinâmica que partiu da construção imagética do próprio professor supervisor de História, feita pelos alunos, combinando teoria e imagens.

$\mathrm{Na}$ segunda parte, o estagiário estimularia a participação dos discentes, que teriam que adivinhar qual imagem pertencia ao continente africano, colocando em evidência os debates de estereótipos desconstruindo-os - em torno da urbanística, miséria, religião e geografia das regiões africanas, compreendendo suas representações 9 .

No derradeiro momento, seria projetado pelo estagiário, um esquema de como são formadas as representações, para que os discentes produzissem uma pergunta com base no que fora debatido, a fim de alimentar a roda de conversa, e fizessem uma avaliação livre sobre aquela aula ${ }^{10}$.

\section{Relatos das aulas expositivas-dialogadas}

Como gerar identificação com uma turma ao preparar uma aula para estágio? Com base nas observações feitas pelo estagiário da forma em que o professor supervisor e até mesmo orientador regiam suas aulas, o estágio proporcionou uma oportunidade para pensar em como imergir os discentes em um debate expositivo com os objetivos de compreender o conceito de representação e identificar sua construção imagética nos livros didáticos.

Partindo dessa perspectiva, o estagiário tivera que sistematizar uma estratégia didática que fosse uma ação de representar e que não fugisse ao conhecimento dos discentes das turmas do $5^{\circ}$ ano. Logo, começar a aula de uma forma objetiva, divertida e dialogada foi o caminho escolhido pelo estagiário. Discentes das turmas de $5^{\circ}$ ano e estagiário G.M.F., construíram, como planejado, uma representação imagética do professor supervisor C.A.M., por meio da qual compreenderiam a práxis do ato de representar. Em seguida, foram separados de cinco a dez minutos da aula para, com

\footnotetext{
${ }^{9}$ Estratégia didática inspirada pela historiadora Ivete Batista da Silva Almeida.

${ }^{10}$ Tanto o feedback quanto a avaliação que acarreta em um produto, no caso do exercício de formular as perguntas, foram feitos de formas anônimas.
} 
exemplos cotidianos, aplicar o conceito de representação supracitado em Guarato (2009) entendendo, entre risos, as generalizações nas representações e, o mais importante, seu efeito de verdade dentro do repertório da experiência fenomenológica da constituição dos sujeitos. Logo, o desenvolvimento da aula atinge seu ápice: compreender que as representações não eram verdades, e, sim, fragmentos de percepções de um grupo sobre o objeto representado.

A partir dessa problemática, tem lugar, então, a seguinte pergunta proposta pelo estagiário aos discentes dos $5^{\circ}$ anos: como o continente africano era imageticamente representado nos livros didáticos? Após o instrumental do conceito de representação, os discentes começaram a observar imagens projetadas do referido continente como um apêndice tangente da História da Europa, inclusive sem muitas fotos contemporâneas da África.

Destaca-se um momento marcante: ao projetar no quadro da sala de aula os mapas político e étnico, de forma sobreposta, os discentes observaram com espanto a generalização que a divisão territorial africana apresenta em relação às etnias de cada território - considerando a própria disposição geográfica das regiões dos países africanos, que não correspondem às divisões étnicas.

Outras indagações foram realizadas, que serviriam como ponte para a roda de conversa: Qual o repertório imagético dos discentes sobre a África contemporânea? Quais efeitos de verdade eles tomam como reais?

Para isso, a estratégia utilizada pelo estagiário partiu do uso da ferramenta lúdica com um jogo de imagens, relacionando a África contemporânea com outras regiões do mundo, com o intuito de confrontar a ideia de que o continente africano é um monólito da antiguidade e de miséria. Com a pergunta "África?" projetada nos slides, os discentes tiveram que adivinhar quais das fotos pertenciam ao continente africano, passando pelos eixos das estéticas urbana, da miséria e de expressões de religiosidade. 
A estética urbanística e da miséria gerou confusões na grande maioria dos discentes, como na projeção de imagens do centro do Cairo, no Egito, ao lado de uma favela em Madri, na Espanha. As turmas ficaram divididas entre escolher a favela ou a região mais contemporânea e "desenvolvida" como África. Revelando os resultados, o efeito de estranhamento possibilitou que o diálogo fosse ampliado: por que, então, a África é representada sempre com miséria? Essas questões foram debatidas.

Seguindo o jogo de imagens, os alunas e as alunas também puderam examinar a estética da religiosidade a partir as seguintes representações: muçulmanos no centro de São Paulo; uma igreja católica em Luanda, na Angola; o candomblé em Minas Gerais; e o Iorubá na Nigéria. Discussões sobre a construção e a reprodução de representações surgiram novamente, assim como acerca do islamismo no Brasil, catolicismo na África e a própria representação que o Brasil tem de si.

Após esse intenso debate, que consumiu em torno vinte minutos de cada aula, no tempo restante, assim como previa o plano de aula, o estagiário pediu para que os discentes elaborassem um roteiro de perguntas orientadas pelos debates desenvolvidos em sala de aula, para posteriormente serem aplicadas na roda de conversa.

Nos derradeiros minutos, os discentes foram orientados a realizar um feedback, alinhado às propostas de uma avaliação formativa, posto que uma devolutiva consiste em um dado manifestado pelo receptor a partir de uma mensagem enviada pelo emissor, favorecendo a avaliação e, consequentemente, promovendo o ensino e as aprendizagens.

Assim, orientados pela importância de uma aprendizagem compartilhada, o questionário continha três perguntas: "O que achou da aula? (Boa, ruim, excelente, péssima?)", "Com base na pergunta anterior: Se a resposta foi boa ou excelente, o que mais gostou? Se a resposta foi ruim ou péssima, o que não gostou?", "Dê sugestões para aula!". 
A simples incorporação dessa orientação na concepção de propostas avaliativas já viabilizaria mudanças significativas na formação de todos os agentes envolvidos, principalmente do estagiário:

... o respeito ao educando, o incentivo e a valorização de seus diversos saberes, a manifestação identitária, a autoria, a autenticidade, a construção, a criatividade, a análise, a reflexão, o aprendizado, a parceria, a corresponsabilidade, o sentimento de pertença e as contribuições do trabalho com a diversidade, a possibilidade de retomada a partir da identificação de fragilidades, buscando sua superação. Nesse sentido, em relação aos alunos, identificamos que tais métodos/ propostas de trabalho podem contribuir para a autorregulação do processo ensinoaprendizagem, por possibilitarem que os educandos compreendam a forma pela qual aprendem melhor, como adquirem autonomia para se autoavaliarem e avaliarem seus pares e professores. Esse tipo de trabalho possibilitou aos alunos visualizar o esforço almejado e conquistado, a especificidade de seus trabalhos e os avanços obtidos durante o percurso, assim como identificar os limites e desafios existentes, em um processo de autocomparação com as próprias produções. Do mesmo modo, os diferentes tipos de métodos de avaliação/propostas de trabalho nos levaram a perceber que eles contribuíram para que os docentes conhecessem mais e melhor seus alunos, os limites e potencialidades advindos dos processos de ensino e de aprendizagem, bem como a reflexão e análise sobre eles para o ajuste dos objetivos e finalidades de ensino. (CAMARGO, 2014, p. 311).

Após a regência, o estagiário constatou por meio de dados, que os discentes gostaram bastante da exposição, do conteúdo, da explicação, da interatividade, da didática e das propriedades lúdicas da aula. Também demonstraram um forte interesse no uso do lúdico - como jogos, brincadeiras, vídeos, desenhos, trabalhos em grupos - e sugeriram alguns pontos importantes, como o aprimoramento da postura em sala, volume da voz, emprego de vocabulário adequado e a acessibilidade de determinados usos de recursos pedagógicos, como os slides.

Durante o intervalo, estagiário e professor supervisor fizeram uma avaliação informal da experiência da regência, destacando alguns aspectos didáticos, mas também a importância da expressão corporal e da entonação de voz, convergindo com as sugestões dos próprios discentes. 
Ademais, ao estagiário e professor supervisor consultaram as perguntas que os discentes fizeram para a roda de conversa. Em linhas gerais, as mesmas estavam voltadas para a diversidade do continente, como: "Qual cidade você mora no continente Africano?", "Como foi a independência na sua região lá na África?", "Você é de qual religião?”, “Como funciona o sistema de socorro de seu país?", "Como é o sistema político da sua região", "Quando chegou no Brasil, sofreu preconceito?".

Faltando poucos minutos para terminar o horário, respeitando a tradição e a metodologia de trabalho desenvolvida pelo professor supervisor, o estagiário aderiu aos Minutos do Bem (breve tempo, no final das aulas, concebido pelo professor supervisor, para sociabilidade entre aluno-aluno e professor-aluno). Os Minutos do Bem ocorreram em todas as aulas e foram importantes oportunidades de compartilhamento de experiências.

Algumas considerações ainda se fazem pertinentes.

Nessa experiência, tanto estagiário quando professor supervisor perceberam claramente como, na formação realizada ao longo de toda uma carreira, o docente deve ter como parâmetro um diálogo qualificado não apenas com seus colegas de trabalho, mas também com todos os agentes oriundos do ambiente escolar, com o intuito de assumir uma posição de facilitador do processo de aprendizagem: humanidades e humanos são sinônimos de movimento, logo, uma prática interpessoal nunca deve ser centrada em um único indivíduo.

Em uma simples manhã, observou-se um notório desenvolvimento em relação à primeira aula do estagiário, principalmente no que concerne à prática docente e à forma de lidar com os discentes. Desse modo, muitos estudantes atingiram o objetivo de ensino proposto no plano de ensino proposto pelo grupo ao qual o estagiário fazia parte, procurando manter uma relação empática, aproveitando e adaptando as questões e as diferenças entre as turmas que surgiam ao longo das atividades, otimizando o espaço de debate até mesmo para pensar o sentido - não teleológico - da História. 
Nada disso seria possível sem uma boa relação entre estagiário, professor supervisor, professor orientador, discentes e com os demais agentes envolvidos no processo formativo, demonstrando a importância de uma aprendizagem compartilhada dessa rica teia escolar na qual estávamos inseridos.

\section{Roda de conversa}

Dentro dessa proposta formativa do ensino e de aprendizagens compartilhadas, estendendo essa rede colaborativa de trabalho em prol de um desenvolvimento da consciência histórica, o estagiário foi convidado a vivenciar o que já estava previsto no item VI da LDB: "Colaborar com as atividades de articulação da escola com as famílias e a comunidade" (BRASIL, 1996).

Em suma, a ideia desta seção é pensar no diálogo conjunto de professor supervisor-estagiário, no processo de formação mútua, incluindo também discentes e comunidade. Desse modo, a primeira tarefa foi entrar em contato com os intercambistas africanos e convidá-los para uma atividade escolar, formando um grupo de seis indivíduos de nacionalidades distintas.

Enquanto isso, era planejado uma vivência metodológica a partir da plataforma do projeto Bairro-escola, vigente na própria instituição de ensino e coordenada pelo professor supervisor, consistindo em outra dinâmica de observação e atuação, dando continuidade aos trabalhos de regência do estagiário.

Grosso modo, o projeto consistia na concepção da importância de explorar outros espaços educativos, em que os habitantes do entorno da escola assumiriam um papel formativo na vida dos estudantes da escola.

Neste caso, como se tratava de uma aula em que se contemplavam os conteúdos étnicos raciais, previstos na proposta curricular da própria 
disciplina, percebeu-se o potencial educativo dos intercambistas africanos da UFU que estudavam muito próximos ao Colégio de Aplicação.

Portanto, após a aula de estágio acerca das representações sobre o continente africano, considerando a semana de reflexões advindas da semana da Consciência Negra em todo o país, a próxima etapa foi contatar esses "vizinhos" da escola, para que participassem da roda de conversa. Para tanto, tivemos o apoio da DIPAE (Divisão de Promoção de Igualdades e Apoio Estudantil), setor da própria universidade, que nos indicou alguns nomes oriundos do programa de intercâmbio internacional da instituição.

Professor supervisor e estagiário entraram em contato com universitários provenientes da Angola, Guiné-Bissau, Congo, Camarões, Costa do Marfim, República Democrática do Congo, Congo, Cabo Verde, dentre outros, buscando sempre a formação de um grupo plural.

Infelizmente, até o dia da atividade, houve muitas desistências ${ }^{11}$, permanecendo apenas a guineense J. G., recém formada em Direito (2017-1), pela UFU. O foco na diversidade foi substituído por um olhar particular sobre a convidada africana. Além do mais, J.G. havia participado do projeto de extensão de apoio ao ingresso no ensino superior, o AFIN, "um projeto com aulas gratuitas para estudantes que estejam cursando ou já concluíram o terceiro ano do Ensino Médio em uma escola pública de Uberlândia ou da região" (BRITO, 2017) - esse foi um importante projeto não apenas para a formação discente do ensino superior, mas também para proporcionar estrutura e uso de um bem público acessível à comunidade -; facilitando em muito o processo relacional com os discentes.

$\mathrm{Na}$ primeira turma, no $5^{\circ}$ ano $\mathrm{C}$, os alunos e as alunas estavam eufóricos para conhecer a intercambista, que soube manejar e levar muito bem a discussão, permanecendo em torno das perguntas referidas na etapa anterior e obtendo uma aproximação de realidades, principalmente a respeito das brincadeiras de sua infância e sobre seu momento de adaptação

${ }^{11}$ É válido ressaltar que os principais motivos das desistências foram outras atividades dos próprios estudantes. Também merece destaque o fato de que havia receptividade e interesse de todos em participar. 
em Uberlândia, quando foi vítima de racismo. J. G. também explicou um pouco sobre uma das línguas da região de Guiné-Bissau, utilizando o quadro como ferramenta didática de uma maneira dinâmica.

Durante o intervalo, professor supervisor, estagiário e a vizinha africana, foram, como de costume, até a região das quadras, onde fizeram parte de um recreio orientado. Algumas estudantes do $5^{\circ}$ ano $\mathrm{B}$ quiseram apresentar seus locais favoritos no espaço escolar, reiterando a importância do intercâmbio em outros espaços educativos.

Após o intervalo, a atividade ocorrera no $5^{\circ}$ ano B. Assim como na turma anterior, os discentes procuraram, através das perguntas, compreender a representação da região da África por meio do relato da convidada, pensando principalmente a temática cultural, como alimentação, jogos e festas. Porém, nessa sala, os discentes não abordaram diretamente a temática de racismo e preconceitos, necessitando o professor supervisor incitar esse debate.

Por fim, o $5^{\circ}$ ano A trouxe indagações específicas que perpassavam pelas curiosidades culturais dos alunos, que tentavam compreender a Guiné-Bissau de forma comparativa com o Brasil.

Finalizando esta seção, dois pontos importantes devem ser ressaltados, um subjetivo e outro objetivo sobre as aulas de regências e as observações ativas na referida atividade. Subjetivamente, a roda de conversa proporcionou uma importante experiência no tocante à avaliação oral, evidenciando como os sujeitos se apropriaram - no sentido de aprendizagem vygotskyano - das discussões de representação no debate. Por outro lado, objetivamente, também constatamos a diversidade inerente às três turmas, influenciando, principalmente, a necessidade de ser pensada a relação professor-aluno em seu âmbito de desenvolvimento psicológico, fazendo uso de teorias adequadas para conseguir alcançar um diálogo de qualidade. 


\section{Reflexões e percepções em torno da educação inclusiva}

Nesta derradeira seção deste relato de experiência, tem como objetivo refletir sobre uma temática que, até mesmo dentro dos cursos de licenciatura, não é abordada de maneira direta nas aulas. Trata-se de práticas voltadas à educação inclusiva, partindo da experiência que o estagiário tivera com um discente, que, doravante, neste relato, se chamará, ficcionalmente, Paulo. O estudante apresentava uma deficiência intelectual e sérios problemas cardíacos, sendo obrigado a usar uma válvula dentro de seu corpo infantil, apesar dos seus 14 anos de idade. Infelizmente, ele veio a óbito algumas semanas depois da conclusão do estágio.

Alguns meses antes, durante o "III seminário internacional: Desafios do trabalho e educação no século XXI: Os 100 anos da revolução russa", ocorrido no segundo semestre de 2017, no campus Santa Mônica da UFU, no grupo de trabalho 2, "Educação básica, trabalho e formação docente", na fala da professora da E.E.P.J.F.S. (Uberlândia - MG), Ana Abadia dos Santos Mendonça, com o trabalho "Formação docente para a educação inclusiva", ressaltou que não se deve ter pena do estudante com deficiência, mas compreender seus limites e trabalhar para que ele se desenvolva dentro do tempo do sujeito.

Tendo como premissa essa assertiva, assim como o professor supervisor, quando o estagiário deparava-se com Paulo na sala de aula, ou até mesmo nos corredores do colégio, procurava-se responder às suas expectativas no papel de estagiário em formação. Contudo, durante a prática de ensino, infelizmente, não se teve tempo hábil para desenvolver uma proposta pedagógica adequada.

O contato direto do estagiário com Paulo ocorreu durante a experiência de observação da oficina de um colega da equipe da prática de ensino e, posteriormente, como discente na aula de regência ministrada. Chegaram ao $5^{\circ}$ ano $\mathrm{C}$ o estagiário e o professor orientador, durante a organização da oficina. Paulo estava sentado e observando. Logo ele 
identificou a presença dos novos corpos no espaço. O mesmo se aproximou, querendo se sentar junto a eles. Naquele dia, o profissional que o acompanhava não estava presente.

Teve, no diálogo entre os três, certa dificuldade em compreender o que Paulo falava e as relações que fazia, já que, ele empregava significados a elementos do ambiente que eram singularmente potencializados à sua maneira de sistematizar o universo ao qual estava inserido.

Com muito cuidado eles interagiram. O estagiário estava com uma jaqueta azul e o professor orientador de blusa verde. Assim foram denominados por Paulo de Azul e Verde.

Em seguida, Paulo ficou interagindo com os números do armário que guardava o material pedagógico na sala. Ele identificava as formas e queria que seus novos amigos confirmassem se correspondia aos numerais que ele conhecia. Paulo acertou quase todas, porém demonstrou dificuldade entre o número dois (2) e cinco (5), talvez por conta de sua similaridade. Azul e Verde buscaram instigar Paulo em seu jogo de identificações, com o intuito de mostrar a diferença de forma entre os números, uma tarefa que tomou completamente a atenção de ambos, colocando-os a refletir sobre a maneira como poderia ser feita a integração de um discente como Paulo em uma regência, e, ainda, sem acompanhamento especializado.

Por orientação do professor supervisor, fora requisitada uma folha para que Paulo pudesse desenhar, uma atividade que ele gostava muito. Pedindo ajuda ao Azul e ao Verde, o garoto escolheu as cores que se aproximavam daquilo que nos nomeou, novamente, demonstrando sua tentativa de identificar os elementos do meio ao qual estava inserido.

Paulo começou a perguntar os formatos das letras para que ele desenhasse, posto que queria escrever o nome dele. Desse modo, o estagiário procurara algo próximo de recurso pedagógico para que Paulo pudesse enxergar o formato, porém nada encontrara. Então fizera uso do smartphone para pesquisar as letras, e funcionou! Paulo ficou o resto da oficina pedindo as formas, sendo que algumas ele teve dificuldade de desenhar. Assim, 
sempre que o momento permitia, o estagiário tentara auxiliar, com suas questões ou dificuldades, não deixando passar signos divergentes na relação com sua forma e conteúdo.

Assim como fazemos com qualquer outro estudante, procuramos aumentar a dificuldade do exercício de identificação de Paulo. O uso do smathphone gradualmente fora reduzido como referencial para as representações geradas por Paulo das letras, fazendo com que ele identificasse as formas pelas representações que ele desenhara (com o sentido de ele reconhecer-se no meio). E, por fim, a tentativa de estimulo do estagiário em fazer com que o discente desenhasse as letras sem ter nenhuma referência de formato.

Pensando através do prisma piagetiano do desenvolvimento cognitivo, Paulo, que estava no $5^{\circ}$ ano, embora tivesse a idade real de 14 anos, aparentava estar no final do estágio operatório concreto, demonstrando evidências ao se relacionar com os sujeitos e objetos do meio externo a si, tornando-se capaz, em espectros, "de tratar os objetos como símbolos de outras coisas" (FONTANA, 1997, p.50), sendo que o "desenvolvimento da representação cria as condições para a aquisição da linguagem, pois a capacidade de construir símbolos possibilita a aquisição dos significados sociais (das palavras) existentes no contexto em que ela vive." (Idem, 1997, p. 50); ou seja, ele se encontrara aparentemente por esse prisma, no período pré-operatório (dois a sete anos).

Para o estagiário manter uma relação com Paulo, teria que entender como ele representava o mundo e, com o intuito de trabalhar dentro de suas limitações, auxiliá-lo no que ele necessitasse, respeitando também seus próprios limites, sem causar confusões no processo de aprendizagem de Paulo. Reiterando, seria preciso pensar a partir dele. O uso de ferramentas tecnológicas digitais, como o smartphone, poderia ser substituído por ferramentas analógicas do alfabeto e números, embora o estudante demonstrasse um forte interesse por equipamentos eletrônicos. Por fim, eles podem ser importantes aliados para gerar um canal de comunicação entre 
professor-aluno. Com isso, é indispensável a preparação do docente em relação às particularidades de cada estudante, como ficou escancarado no caso de Paulo.

Além do mais, por mais que o exercício prático exija uma multidimensionalidade do professor, o atendimento especializado ao discente com deficiência é crucial, não por uma questão disciplinar, mas para auxiliar o estudante na imersão da aula.

A experiência em sala com Paulo foi rápida, não atingindo trinta minutos, mas certamente ficará marcada para sempre na teia formativa do estagiário.

\section{$5 \mathrm{O}$ instante e a formação compartilhada}

...o tempo é uma realidade encerrada no instante e suspensa entre dois nadas. O tempo poderá sem dúvida renascer, mas primeiro terá de morrer. Não poderá transportar seu ser de um instante para outro, a fim de fazer dele uma duração. O instante é já a solidão... É a solidão em seu valor metafisico mais despojado. Mas uma solidão de ordem mais sentimental confirma o trágico isolamento do instante: por uma espécie de violência criadora, o tempo limitado ao instante nos isola não apenas dos outros, mas também de nós mesmos, já que rompe nosso passado mais dileto. (BACHELARD, 2010, p.15-16).

A citação acima, retirada da obra A instituição do instante (1932), em que o filósofo francês Gaston Bachelard discute a ideia de metafísica do historiador francês Gaston Roupnel, passa um sentimento que deve ser expresso para concluir este relato de experiência, refletindo em torno do instante da regência.

Como apontado por Bachelard, o instante se encontra entre "nadas", o passado e o futuro, sendo ele um eterno presente isolado, experienciado conscientemente pelas erupções sensíveis entre o meio e a memória afetiva consciente e inconsciente de outros instantes que irradiam o comportamento individual instantâneo. 
Metaforicamente, pensando sobre o ato da regência, como muito bem ressaltado pelo professor supervisor, deixará impressões e contribuirá profundamente para a formação docente do estagiário. Sendo, assim como um aglomerado de instantes, esses fragmentos serão reativados através da memória afetiva do profissional durante o exercício da prática docente.

A regência do estagiário G. M. F. no Colégio de Aplicação da UFU foi sua primeira aula, e, inevitavelmente, existia uma primeira sensação de ansiedade, desconhecimento do novo e de curiosidade para saber se o que havia sido planejado iria dar certo na prática. Lidar com esses sentimentos também fazem parte do ofício docente, pois eles influenciam no fluxo da aula e na forma de se relacionar com os agentes da comunidade escolar, principalmente com os discentes.

Ao mesmo tempo em que a aula é uma atividade solitária, não se deve encarar o conceito de solidão com toda a carga simbólica comum que ela possui na contemporaneidade, pois, neste caso, como em outros, a solidão é necessária para formação, não apenas do ofício, mas de todas as esferas da vida.

No entanto, a condição humana chega a ser um paradoxo, pois está constantemente compartilhando suas solidões, formando a pluralidade, fragmentações e espectros sociais.

Nesse sentido, como equilibrar esses anseios para o desenvolvimento das atividades profissionais? Como posto por Bachelard, os instantes vivem entre "nadas", e o que viria a ser o instante da regência, antes, um vazio, fora preenchido em ideias objetivas e subjetivas do pensamento do regente estagiário.

Partindo dessa experiência, para sanar tais questões, é crucial o entendimento da importância da relação compartilhada de formação inicial e continuada.

No caso do estágio, a inter-ação com professores experientes, colegas de curso, discentes heterogêneos, uma jovem africana, além de outros agentes dessa complexa trama formativa, serviram para evidenciar a 
circulação teórica e prática por meio do ensino em História, contribuindo, através desta formação compartilhada, para composição de profissionais ativos, autônomos e seguros.

$\mathrm{E}$, principalmente, estimulando a vontade de exercer o ofício docente, construindo memórias afetivas sadias sobre a experiência de regência, contribuindo para um estado emocional equilibrado, neste caso, do estagiário e futuro profissional, já que o "nada" ainda continua sendo um espaço vazio preenchido por ideias.

\section{Referências}

ALMEIDA, Ivete Batista da Silva. "A África como componente curricular: Representações da África contemporânea nos manuais escolares brasileiros de História e Geografia". In: VII Colóquio Luso-Brasileiro e I Colóquio Luso-AfroBrasileiro de Questões Curriculares, 2014, Braga/Portugal. Anais do VII Colóquio Luso-Brasileiro e I Colóquio Luso-Afro-Brasileiro de Questões Curriculares. Braga: UMINHO, 2014.

BACHELARD, Gaston. A instituição do instante. Campinas: Verus Editora, 2010.

BRASIL. Lei $\mathrm{n}^{\circ}$ 5.692, de 11 de agosto de 1971, Fixa Diretrizes e Bases para o ensino de $1^{\circ}$ e $2^{\circ}$ graus, e dá outras providências. Este texto não substitui o publicado no DOU de 12.8.1971 e retificado em 19.8.1971. Disponível em: http://www.planalto.gov.br/ccivil_03/leis/L5692.htm.

. Lei no 9.394, de 20 de dezembro de 1996. Estabelece as diretrizes e bases da educação nacional. Diário Oficial da república Federativa do Brasil. Brasília, DF, 23 de dezembro de 1996. Disponível em: http://www.planalto.gov.br/ccivil 03/leis/L9394.htm.

Constituição (1982). Decreto $\mathrm{n}^{\circ}$ 87.497, de 18 de agosto de 1982. Regulamenta a Lei № 6.494, de 07 de Dezembro de 1977, Que Dispõe Sobre O Estágio de Estudantes de Estabelecimentos de Ensino Superior e de $2^{\circ}$ Grau Regular 
e Supletivo, nos Limites Que Especifica e Dá Outras Providências. Brasília, Disponível em: < http://www.planalto.gov.br/ccivil_03/decreto/d87497.htm>. . Constituição (2013). Lei $n^{0}$ 10639, de 10 de janeiro de 2013. Altera A Lei no 9.394, de 20 de Dezembro de 1996, Que Estabelece As Diretrizes e Bases da Educação Nacional, Para Incluir no Currículo Oficial da Rede de Ensino A Obrigatoriedade da Temática "História e Cultura Afro-brasileira", e Dá Outras Providências. Brasília, Disponível em: <http://www.planalto.gov.br/ccivil_03/leis/2003/L10.639.htm>.

Secretaria de Educação Fundamental. Parâmetros curriculares nacionais: História / Secretaria de Educação Fundamental. Brasília: MEC /SEF, 1998.

BRITO, Letícia (Minas Gerais). Universidade Federal de Uberlândia (Ed.). UFU oferece curso pré-Enem gratuito: Projeto é voltado para alunos de escolas públicas. 2017. Disponível em: <http://www.comunica.ufu.br/noticia/2017/07/ufu-oferececurso-pre-enem-gratuito>. Acesso em: 30 nov. 2017.

CAMARGO, Clarice Carolina Ortiz de. Métodos de avaliação formativa: desatando nós e alinhavando possibilidades. 2014. 354 f. Dissertação (Mestrado em Educação) - Programa de Pós-Graduação em Educação, Universidade Federal de Uberlândia, Uberlândia, 2014.

BUIATTI, Viviani Prado. "Módulo5: Rogers: o ensino centrado no aluno". In: Apostila Psicologia da Educação II, Coleção Pedagogia a Distância UFU/UAB. Uberlândia - MG: Universidade Federal de Uberlândia, Universidade Aberta do Brasil, 2013.

FONTANA, Roseli. "A abordagem histórico-cultural". In: Psicologia e trabalho pedagógico. São Paulo: Atual, 1997.

"A abordagem piagetiana". In: Psicologia e trabalho pedagógico. São Paulo: Atual, 1997.

FOUCAULT, Michel. "Verdade e Poder". In: Microfísica do poder. Rio de Janeiro: Graal, lê livros, 1982. 
FREIRE, Paulo. Pedagogia da Autonomia: saberes necessários à prática educativa. São Paulo: Paz e Terra, 1996.

GUARATO, Rafael. "Considerações acerca do conceito de representação e seus usos historiográficos”. In: Anais do $3^{\circ}$. Seminário Nacional de História da Historiografia: aprender com a História? Ouro Preto: Edufop, 2009.

KOSELLECK, Reinhart. Futuro Passado: contribuição à semântica dos tempos históricos. Rio de Janeiro: Contraponto/ Ed. da PUC-RIO, 2006, p. 309-310.

LEITE, Miriam Soares. "Yves Chevallard e o conceito de transposição didática". In: LEITE, M.S. Recontextualização e transposição didática: introdução à leitura de Basil Berstein e Yves Chevallard. Araraquara: Junqueira \& Martins, 2007.

RÜSEN, Jorn. "Pragmática - a constituição do pensamento histórico na vida prática”. In: Razão histórica. Teoria da História: os fundamentos da ciência histórica. Brasília: Editora Universidade de Brasília, 2001.

THOMPSON, E.P. “Tempo, disciplina de trabalho e capitalismo industrial”. In: Costumes em comum. São Paulo: Companhia Das Letras, 1998.

UBERLÂNDIA. Colégio de Aplicação - Escola de Educação Básica da Universidade Federal de Uberlândia. Ministério da Educação (Ed.). ESEBA. 2017. Disponível em: <http://www.eseba.ufu.br>. Acesso em: 12 jul. 2017.

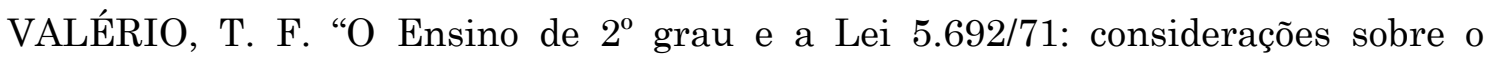
processo de implementação da reforma no Estado do Paraná. ” In: VI Congresso luso-brasileiro de História da educação. 6., Uberlândia, MG, 2006, Anais, p.5633. 